\section{Unleashing NK cells}

\section{By Lev Osherovich, Senior Writer}

A French-led team has devised a new strategy to increase the activity of NK cells, a type of innate immune cell that combats infections and tumors. The approach involves antagonizing an NK cell surface protein called NCR1 that ordinarily holds the NK cells in check. ${ }^{1}$ The findings offer a new entry point into modulating innate immunity, and Innate Pharma S.A. is collaborating with the team to explore potential therapeutic applications.

NK cells "distinguish normal cells from target cells infected by microbes or tumor cells using two types of receptors-activating and inhibitory ones," said team co-leader Eric Vivier. "Normal cells express a lot of inhibitory
"Normal cells express a lot of inhibitory molecules presence or absence of these inhibitory signals governs whether the NK cells kill or spare a potential target cell." -Eric Vivier, Aix-Marseille University that engage NK cells. The

"We asked whether we could recapitulate these genetic effects using a mAb directed against NCR1," said Vivier. "The good news is that we can recapitulate the mutations. We see that NK cell activity is boosted by this antibody."

Results were reported in Science. The team was co-led by Sophie Ugolini, senior researcher at the Institut National de la Santé et de la Recherche Médicale (INSERM). INSERM has filed patents covering the Ncr1-targeting $\mathrm{mAb}$ and is negotiating a license with Innate Pharma.

\section{Natural utility}

The findings are unexpected because NCR1 previously was thought to be a stimulatory receptor. Now, the receptor appears to have different effects on NK cell activity depending on when and where it is targeted.

"NCR1 is one of the main activating receptors of NK cells. Thus, the results presented in the paper are sort of surprising," said Innate Pharma CSO and cofounder François Romagné. "Why would blocking an activating receptor cause gain of function of NK cells-this is counterintuitive."

The answer, he said, appears to be in the timing of NCRl's activity during the or absence of these inhibitory signals governs whether the NK cells kill or spare a potential target cell."

Vivier is director of the Immunology Center of Marseille-Luminy, professor of immunology at Aix-Marseille University's medical school and cofounder of Innate Pharma.

The French-led team found that NCR1 (natural cytotoxicity triggering receptor 1; NKP46; CD335) is the likely receptor for such an inhibitory signal. Antagonizing NCR1 increased the innate immune response against a range of threats including tumor cells and the murine version of cytomegalovirus (CMV), a model viral pathogen.

\section{Mutant mouse}

In a genetic screen for mouse mutants with unusual innate immune responses to CMV, the French team found a mouse strain with hyperactive innate immunity. When exposed to murine CMV, the animal had more robust cytokine production and better survival than similarly treated wild-type controls. The team traced the phenotype to a loss-of-function mutation in Ncr1.

The Ncr1-mutant mice appeared to have an otherwise normal immune system.

In cell culture, NK cells derived from mice with the Ncrl mutation also had a more vigorous response than wild-type NK cells against cocultured tumor cells and cells infected with an intracellular bacterium expressing a model antigen.

Vivier suspected pharmacological inactivation of Ncrl could produce similar results. To find out, his team made a murine mAb against Ncrl, injected it into mice and extracted NK cells. Indeed, the NK cells were more active against tumor cells in culture than NK cells from mice treated with a control mAb. development of NK cells. He said the lack of NCR1 activity in Vivier's mutant mice and in animals treated with anti-NCR1 mAbs causes NK cells to develop with a lower threshold for activation, leading to a hypervigilant innate immune response.

However, it is possible that blocking NCR1 in mature NK cells could prevent their activation, said Romagné. Vivier's mAb thus "would not be very easy to use as a therapeutic agent."

Instead, he said the mAbs could be used prophylactically to prime a more potent innate immune response in patients undergoing hematopoietic cell reconstitution following bone marrow transplantation. He noted that CMV infections are a significant concern in such patients.

Innate Pharma has a panel of mAbs that block various members of the killer cell immunoglobulin-like receptor (KIR) family, which are NK cell proteins that play a purely inhibitory role.

Last year, Innate Pharma partnered with Bristol-Myers Squibb Co. to co-develop the biotech's lead compound, the KIR-targeting mAb IPH2101, which is in Phase I testing for acute myelogenous leukemia (AML).

Vivier is open about which indications the approach will be most useful in treating. He said his team is now testing the effect of antagonizing NCR1 in influenza, cancer and inflammation.

Another open question is what the natural ligand for NCR1 is and whether that protein can be targeted to achieve effects similar to those caused by blocking NCR1.

Vincent Serra, CEO, CSO and cofounder of Wittycell S.A.S., said that although antagonizing NCR1 could improve the innate immune response against a variety of pathogens and tumors, having a hyperactive innate immune system "could degrade the specificity of the acquired immune response." 


\section{ANALYSIS}

\section{TARGETS \& MECHANISMS}

He cited evidence in Vivier's paper that NCR1-mutant mice had lower $\mathrm{T}$ cell responses compared with wild-type animals. These data, said Serra, are in line with evidence that chronic activation of innate immunity leads to an anergic or blunted acquired immune response. This occurs because $\mathrm{T}$ cells, which are normally activated by brief bursts of innate immune activity, become insensitive to constant stimulation by NK cells.

Serra said targeting NCR1 could be most useful in patients with HIV who are unable to mount an effective acquired immune cell response against pathogens but still have working innate immune systems. He also said the receptor could be a good target for vaccine adjuvants.

Wittycell is developing glycolipid vaccine adjuvants that stimulate NK T cells, which resemble NK cells. WTCc, the company's most advanced adjuvant, is in Phase I testing for cancer and viral indications.
Osherovich, L. SciBX 5(4); doi:10.1038/scibx.2012.89

Published online Jan. 26, 2012

\section{REFERENCES}

1. Narini-Mancinelli, E. et al. Science; published online Jan. 20, 2012; doi:10.1126/science.1215621

Contact: Sophie Ugolini, Aix-Marseille University, Marseille, France e-mail: ugolini@ciml.univ-mrs.fr

Contact: Eric Vivier, same affiliation as above

e-mail: vivier@ciml.univ-mrs.fr

COMPANIES AND INSTITUTIONS MENTIONED

Aix-Marseille University, Marseille, France

Bristol-Myers Squibb Co. (NYSE:BMY), New York, N.Y. Immunology Center of Marseille-Luminy, Marseille, France Innate Pharma S.A. (Euronext:IPH), Marseille, France Institut National de la Santé et de la Recherche Médicale, Marseille, France

Wittycell S.A.S., Reims, France 